\title{
Elevated blood lead and cadmium levels associated with chronic infections among non-smokers in a cross-sectional analysis of NHANES data
}

\author{
Whitney S. Krueger ${ }^{1,2}$ and Timothy J. Wade $3^{3^{*}}$
}

\begin{abstract}
Background: Experimental animal studies, in vitro experiments, and clinical assessments have shown that metal toxicity can impair immune responses. We analyzed data from a United States representative National Health and Nutrition Examination Survey (NHANES) to explore associations between chronic infections and elevated blood concentrations of lead and cadmium among non-smoking NHANES participants.

Methods: NHANES data from 1999 to 2012 were examined and weighted to represent the United States population. Multivariable logistic regression was used to estimate adjusted odds ratios (AOR) and $95 \%$ confidence intervals (CI) for heavy metal associations with seropositivity for Helicobacter pylori, Toxoplasma gondii, and Hepatitis B virus (HBV) infections.

Results: Available 2-year survey cycles for infection seroprevalence varied by pathogen, from 1 to 7 cycles. Available sample size, disease seroprevalence, and participant age range also varied by pathogen of interest. After controlling for demographic characteristics and general health condition, an elevated blood lead level above the survey population median was significantly associated with seropositivity for all three pathogens (AORs $=1.2-1.5$ ). In addition, an elevated blood cadmium level above the median was significantly associated with $\mathrm{HBV}$ ( $\mathrm{AOR}=1.5 ; 95 \% \mathrm{Cl}=1.2-2.0$ ) and $\mathrm{H}$. pylori (AOR $=1.5 ; 95 \% \mathrm{Cl}=1.2-1.7$ ) seropositivity. Age-specific analyses for $\mathrm{H}$. pylori and T. gondii indicated stronger associations among children under 13 years of age, particularly for lead exposure and $\mathrm{H}$. pylori seropositivity, and weaker associations among those over 35 years of age.
\end{abstract}

Conclusions: The results of this cross-sectional human health survey suggest that the immunological effects of lead and cadmium toxicity may be associated with an increased susceptibility to chronic infections.

Keywords: Helicobacter pylori, Toxoplasma, Hepatitis B, Nutrition surveys, Seroprevalence, Heavy metals, Immune system, Immunomodulation

\section{Background}

Human exposure to heavy metals can impair innate and humoral immune responses and lead to an increased susceptibility to infections as well as the development of autoimmune diseases $[1,2]$. Immunomodulatory effects include modifying inflammatory reactions, increasing

\footnotetext{
* Correspondence: wade.tim@epa.gov

${ }^{3}$ United States Environmental Protection Agency, Office of Research and Development, National Health \& Environmental Effects Research Laboratory, Environmental Public Health Division, Chapel Hill, NC 27514, USA

Full list of author information is available at the end of the article
}

cytotoxic responses, and altering the number of circulating lymphocytes, natural killer (NK) cells, and memory cells [3-7]. Prenatal exposures to arsenic and cadmium have been shown to impact genes that may underlie altered infectious disease susceptibility [8]. While direct immunotoxicity of heavy metals has been examined through animal studies, in vitro experiments, clinical assessments, and occupationally-exposed cohort studies [7, 9, 10], few large-scale human epidemiological studies have been performed to assess the adverse immunological effects of heavy metal exposure. In this analysis, 
we examined associations between three common chronic infections: Helicobacter pylori, Toxoplasma gondii, and Hepatitis B virus (HBV) and two ubiquitous heavy metals: Lead $(\mathrm{Pb})$ and Cadmium $(\mathrm{Cd})$.

Naturally found in the earth's crust, lead is used to make batteries, ammunition, pipes, and roofing materials [11]. In the past, it was also added to paint and gasoline. Humans are exposed to lead by inhaling contaminated air, dust, or lead dust, as well as ingesting contaminated soil, water, food, paint chips, and painted toys. Construction sites [12] and hazardous waste sites [13] present occupational exposure risks. Absorption of lead in the body depends on several factors, including nutrition status, health, and age; adults typically absorb up to $10 \%$ of ingested lead while children can retain up to $50 \%$ [11]. Absorbed lead accumulates in mineralizing and soft tissues. Unborn children are at the greatest risk of adverse health effects associated with lead exposure, including low birth weight, premature birth, and abortion. In young children, lead exposure has been associated with decreased intelligence, slowed growth, and hearing problems. Lead has not been shown to be a human carcinogen, but exposure to high levels of lead can result in kidney and brain damage [11].

Also naturally found in the earth's crust, cadmium is a byproduct of smelting and is used in metal plating as well as in making batteries, pigments, and plastics. Cadmium is released into soil, water, and air via mining/refining practices, fertilizer application, fossil fuel combustion, and waste disposal, where it can accumulate in aquatic organisms and agricultural crops [14]. Humans are primarily exposed to cadmium through smoking tobacco and eating contaminated vegetables and grains. Occupational exposure risks through inhalation or accidental ingestion are also of concern. Up to $10 \%$ of ingested cadmium enters the body through the digestive tract [15]. The body can convert cadmium to a non-harmful form; however, at high levels the liver and kidneys can become overloaded. As one of the most toxic heavy metals [16], acute toxicity induces vomiting and diarrhea. Chronic low-level exposures can result in kidney damage and brittle bones [17]. The U.S. Environmental Protection Agency (EPA) has designated cadmium in the $\mathrm{B} 1$ classification as a probable human carcinogen, citing studies linking lung cancer and workers who inhaled cadmium [18].

We analyzed data from the nationally representative National Health and Nutrition Examination Survey (NHANES) to explore associations between H. pylori, T. gondii and HBV seropositivity and elevated blood concentrations of lead and cadmium among non-smoking NHANES participants.

\section{Methods}

Seven 2-year cycles of continuous NHANES data (19992012) [19] were examined. Data were collected using a complex sampling survey design; therefore, approaches recommended by the U.S. Centers for Disease Control and Prevention (CDC) for SAS survey analysis procedures were followed and appropriate sample weights according to the NHANES Analytic and Reporting Guidelines were applied [20].

\section{Seroprevalence data}

Available serology results for H. pylori (1999-2000), T. gondii (1999-2004, 2009-10), and HBV (1999-2012) were examined. For $H$. pylori, sera from eligible participants $\geq 3$ years old were tested by the CDC for immunoglobulin G (IgG) antibodies using an enzyme-linked immunosorbent assay (ELISA) from Wampole Laboratories (Cat \#446404, Carter Wallace, Inc., Cranbury, NJ). A dichotomous seropositivity cut-off was provided by the CDC, in which an optical density at $450 \mathrm{~nm}\left(\mathrm{OD}_{450}\right) \geq 1.1=$ positive and $\mathrm{OD}_{450}<1.1=$ negative [21]. For $T$. gondii, available serum from eligible participants 6-49 years old (19992004) and $\geq 6$ years old (2009-10) were tested by the CDC for IgG antibodies using enzyme immunoassays (EIAs) (Bio-rad, Hercules, CA). A dichotomous seropositivity cut-off was provided by the CDC (1999-2004: IgG $\geq 10 \mathrm{IU} / \mathrm{mL}=$ positive; $\operatorname{IgG}<10 \mathrm{IU} / \mathrm{mL}=$ negative; 2009-2010: IgG $\geq 33 \mathrm{IU} / \mathrm{mL}=$ positive; $\operatorname{IgG}<33 \mathrm{IU} /$ $\mathrm{mL}=$ negative $)$.

Only naturally-acquired HBV infections were considered in this analysis. The commercially-available Ortho $\mathrm{HBc}$ ELISA Test System (Ortho-Clinical Diagnostics, Raritan, NJ), a qualitative ELISA, was used by the CDC to detect total antibodies against hepatitis $B$ core $(\mathrm{HBC})$ antigen. Anti-HBc is present in the serum of $\mathrm{HBV}$ infected individuals and is considered an accurate serological marker of acute, chronic, or resolved HBV infections, but not a marker of vaccine-induced immunity. Participants who had received at least 1 dose of the 3dose $\mathrm{HBV}$ vaccine series, as well as those with unknown vaccine status, were excluded from the analysis. In addition, participants seronegative for anti-HBc but seropositive for antibodies against the HBV surface antigen, a marker for both natural and vaccine-induced immunity, were also excluded from the analysis. NHANES participants $\geq 6$ years old were tested for HBV seroprevalence from 1999 to 2012. NHANES reported HBV serology results dichotomously as positive or negative.

\section{Blood lead and cadmium levels}

For the 1999-2002 survey years, lead and cadmium were simultaneously measured in whole blood by atomic absorption spectrophotometry [22-24] with quantifications based on the measurement of light absorbed at $228.8 \mathrm{~nm}$ and $283.3 \mathrm{~nm}$, respectively, by ground-state atoms of cadmium and lead from either an electrodeless discharge lamp (EDL) or by a hollow cathode lamp 
(HCL) source [25]. For the remaining survey years (2003-2012), whole blood lead and cadmium concentrations were determined by inductively coupled plasma mass spectrometry (ICP-MS), a multi-element analytical technique based on quadrupole ICP-MS technology [26]. The lower detection limits for lead were $0.30 \mu \mathrm{g} / \mathrm{dL}$ for NHANES 1999-2004 and 0.25 $\mu \mathrm{g} / \mathrm{dL}$ for 2005-2012. For cadmium, the limit of detection (LOD) was $0.30 \mu \mathrm{g} /$ dL for NHANES 1999-2002, $0.20 \mu \mathrm{g} / \mathrm{dL}$ for 2003-2010, and $0.16 \mu \mathrm{g} / \mathrm{dL}$ for 2011-2012. Results below the LOD were replaced with a value equal to $L O D / \sqrt{2}$.

Whole blood concentrations of lead and cadmium were assessed by several exposure measurements, including weighted geometric means (GM), levels greater than the study population median, each 2-fold increase (doubling) in concentration, as well as by categories to assess potential nonlinear associations. Quartiles were used for lead, but for cadmium the distribution was skewed due to samples below the limit of detection, so tertiles were used to prevent overlapping values. Metal exposures were stratified by seroreactivity and associations between elevated blood concentrations and seropositivity were examined. Weighted linear correlations between log-transformed lead and cadmium concentrations were measured using Pearson's $r$.

\section{Data analysis}

All analyses were conducted using SAS v9.3 (SAS, Inc., Cary, NC, USA). Because cigarette smoking is highly correlated with toxic heavy metal exposures [27], we restricted our analyses to a domain of non-smokers, defined as having a serum cotinine level $<10 \mathrm{ng} / \mathrm{mL}$ ) [28]. Differences in seroprevalence by participants' demographics were evaluated using the Rao-Scott chi-square test for unadjusted bivariate comparisons. The authors selected covariates of interest a priori, based on previous reports and biologic plausibility, to examine associations with seropositivity, including NHANES cycle, age, gender, race/ethnicity, family income $(</ \geq \$ 20,000)$, country of birth origin (born in the United States or elsewhere), self-reported general health condition (excellent/very good, good, fair/poor), source of tap water in home (municipal or well), crowded housing (total number of individuals living in a household divided by number of rooms in the home, excluding bathroom and kitchen), and ever using a needle to take street/illicit drugs. Because of its role in the replication of bacteria and viruses and its potential impact in the uptake of divalent metals such as lead and cadmium, we also considered serum iron as a potentially important confounding variable [29].

Associations between elevated lead and cadmium blood levels and seropositivity for each pathogen were examined with unadjusted and adjusted logistic regression models to ascertain Rao-Scott chi-square odds ratio (OR) estimates and $95 \%$ confidence intervals $(\mathrm{CI})$.

Multivariable logistic regression was used to account and control for key demographic characteristics and known risk factors, with one model fitted for each serology outcome that included lead or cadmium individually. Covariates with $\mathrm{p}$ values $<0.2$ in a simple logistic model were considered for inclusion in multivariable models. Multivariable models were selected using stepwise backwards elimination of covariates with $\mathrm{p}$ values $>0.05$, with the highest corresponding $\mathrm{p}$-value removed at each step while minimizing the Akaike information criterion (AIC). Collinearity of lead and cadmium levels was confirmed to be insignificant by evaluating the Pearson correlation coefficient, variation inflation factor, and condition number for each model.

Trend tests were performed by regressing the outcome of interest on categorical median concentrations in each percentile (quartiles for lead and tertiles for cadmium) and including all of the same model covariates. Departure from additivity for the joint association of elevated blood lead and cadmium concentrations was assessed by estimating the relative excess risk due to interaction (RERI) and $95 \%$ confidence intervals using the delta method described by Hosmer and Lemeshow [30]. The products of blood lead and cadmium concentrations were added to the logistic regression models to evaluate interaction between the two exposures of interest on a multiplicative scale.

To examine whether the associations differed by age, we stratified the analysis by three age groups (under 13 years of age, 13-35 years of age and over 35 years of age) for $H$. pylori and T. gondii. Age stratification was not considered for HBV because too few children (only 2 were under 13 years of age) were seropositive.

\section{Results \\ Helicobacter pylori}

Exposure and $H$. pylori serology data were available for 5994 non-smoking participants $\geq 3$ years old from a single NHANES cycle (1999-2000) (Fig. 1a). Overall seroprevalence for IgG antibodies against $H$. pylori was $23.1 \%$. Seroreactivity significantly varied by age, race, family income level, country of birth origin, general health condition, and crowded housing (Table 1). The blood lead GM concentration for all participants was $1.50(95 \% \mathrm{CI}=1.43-1.57)$, with $0.8 \%$ of results below the LOD; the GM for blood cadmium was $0.33(95 \% \mathrm{CI}=$ 0.31-0.36), with $35.1 \%$ below the LOD (Table 2). In examining the association between seropositivity and blood concentrations of lead and cadmium (Figs. 2 and 3), the adjusted odds ratios associated with a 2-fold increase in blood lead and cadmium were 1.22 (95 \% CI $=1.12-$ 1.34) and 1.37 (95\% CI $=1.17-1.62$ ), respectively (Table 3 ). 


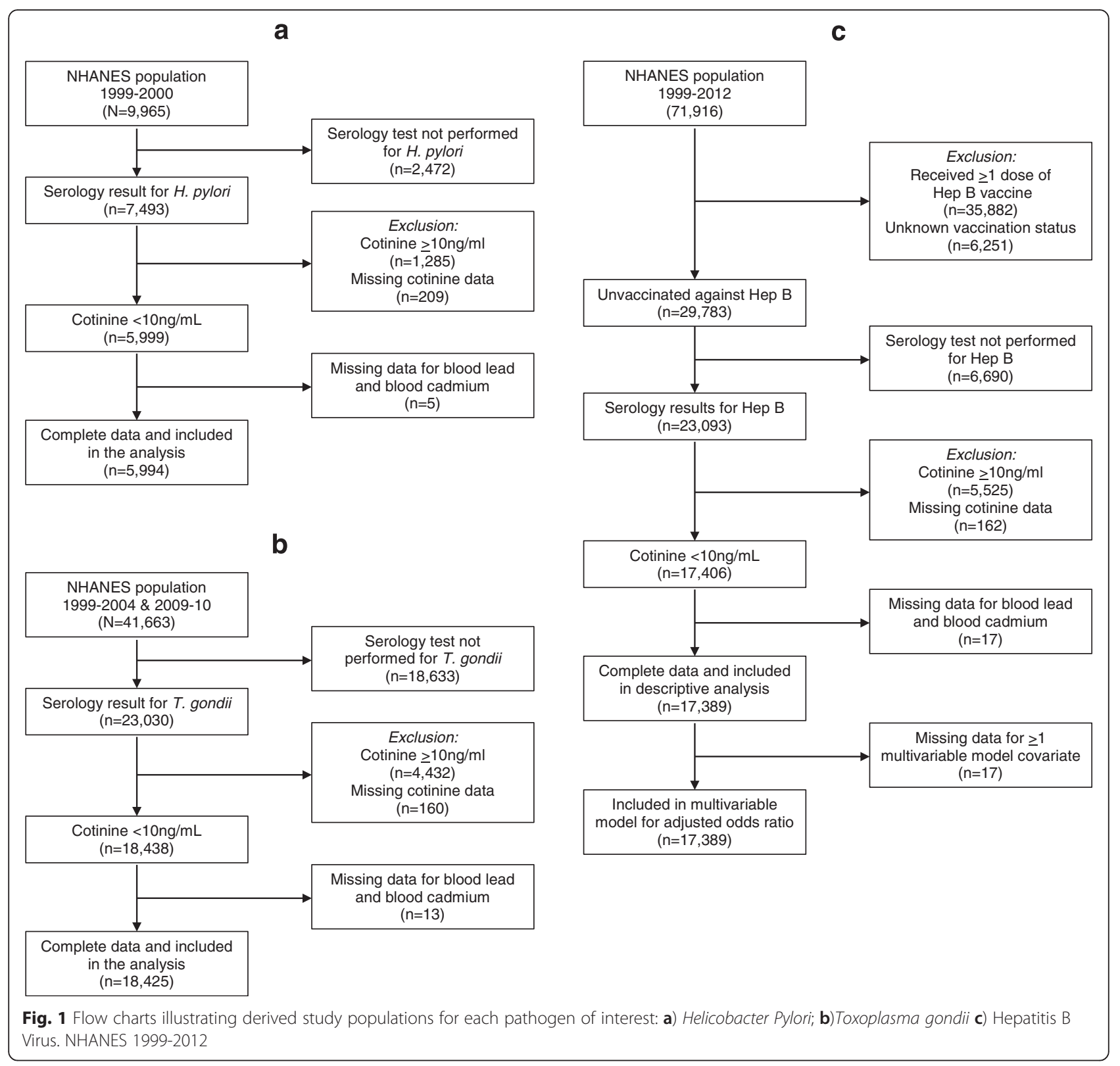

There were significant trends $(p<0.0001)$ in increasing seroprevalence by percentiles of lead and cadmium (Table 3). Lead and cadmium concentrations were only slightly correlated (Pearson's $r=0.26$ ), and no evidence was found to suggest additive or multiplicative interaction between lead and cadmium exposure in association with H. pylori seropositivity (Table 4).

Positive associations between metal exposure and $H$. pylori seropositivity were stronger among children under 13 years old. Children in the highest quartile of lead exposure had markedly higher rates of $H$. pylori seropositivity (Table 5, OR $=21.2,95 \% \mathrm{CI}=8.32-53.8$ ). The strength of the associations for both lead and cadmium declined among those aged 13-35 years. Among those over 35 years old, associations were not statistically significant (Additional file 1: Tables S1 and S2).

\section{Toxoplasma gondii}

For $T$. gondii, 18,425 non-smoking participants $\geq 6$ years old had complete data available from 4 NHANES cycles (1999-2004 and 2009-10) (Fig. 1b). The seroprevalence for IgG antibodies against T. gondii among the study population was $11.0 \%$. Seroreactivity against T. gondii significantly varied by NHANES cycle, age, race, family income level, country of birth origin, general health condition, and crowded housing (Table 1). The blood lead GM concentration for all participants was 1.13 (95\% CI $=1.10-1.16)$, with $0.95 \%$ of results below 
Table 1 Weighted seroprevalence by participant characteristics among nonsmokers, NHANES 1999-2012

\begin{tabular}{|c|c|c|c|c|c|c|c|c|c|}
\hline \multirow[t]{2}{*}{ Characteristic } & \multicolumn{3}{|c|}{ H. pylori } & \multicolumn{3}{|c|}{ T. gondii } & \multicolumn{3}{|c|}{ Hepatitis B virus } \\
\hline & $\bar{N}$ & Positive (\%) ${ }^{a}$ & $p^{\mathrm{b}}$ & $\bar{N}$ & Positive (\%) ${ }^{a}$ & $p^{\mathrm{b}}$ & $\bar{N}$ & Positive (\%) ${ }^{a}$ & $p^{\mathrm{b}}$ \\
\hline Total & 5994 & 23.1 & & 18,425 & 11.0 & & 17,389 & 4.9 & \\
\hline \multicolumn{10}{|l|}{ NHANES cycle years } \\
\hline 1999-2000 & 5994 & 23.1 & - & 4084 & 13.5 & 0.0001 & 2926 & 5.0 & 0.8283 \\
\hline $2001-2002$ & - & - & & 4669 & 8.0 & & 2955 & 4.5 & \\
\hline 2003-2004 & - & - & & 4089 & 9.3 & & 2420 & 5.7 & \\
\hline $2005-2006$ & - & - & & - & - & & 2157 & 5.3 & \\
\hline $2007-2008$ & - & - & & - & - & & 2507 & 4.3 & \\
\hline 2009-2010 & - & - & & 5583 & 12.8 & & 2466 & 5.0 & \\
\hline 2011-2012 & - & - & & - & & & 1958 & 4.9 & \\
\hline \multicolumn{10}{|l|}{ Age (years) } \\
\hline$\leq 13$ & 1721 & 7.2 & $<0.0001$ & 5127 & 3.5 & $<0.0001$ & 613 & 0.4 & $<0.0001$ \\
\hline $14-40$ & 2307 & 20.2 & & 9252 & 10.5 & & 4788 & 2.9 & \\
\hline$\geq 41$ & 1966 & 33.4 & & 4046 & 16.2 & & 11,988 & 5.9 & \\
\hline \multicolumn{10}{|l|}{ Gender } \\
\hline Male & 2785 & 22.7 & 0.5279 & 8529 & 11.5 & 0.1633 & 8171 & 5.5 & 0.0185 \\
\hline Female & 3209 & 23.5 & & 9896 & 10.5 & & 9218 & 4.5 & \\
\hline \multicolumn{10}{|l|}{ Race } \\
\hline Non-Hispanic White & 1912 & 14.6 & $<0.0001$ & 6320 & 9.0 & $<0.0001$ & 8365 & 2.6 & $<0.0001$ \\
\hline Non-Hispanic Black & 1300 & 37.2 & & 4313 & 11.7 & & 3124 & 13.4 & \\
\hline Mexican American & 2586 & 45.2 & & 6967 & 17.2 & & 5083 & 4.3 & \\
\hline Other & 196 & 31.2 & & 825 & 12.4 & & 817 & 27.4 & \\
\hline \multicolumn{10}{|l|}{ Family income } \\
\hline$\geq \$ 20,000$ & 2991 & 18.3 & $<0.0001$ & 10,997 & 9.6 & $<0.0001$ & 10,661 & 4.0 & $<0.0001$ \\
\hline$<\$ 20,000$ & 2650 & 31.5 & & 6725 & 14.3 & & 6027 & 7.4 & \\
\hline \multicolumn{10}{|l|}{ Country of birth origin } \\
\hline United States & 4675 & 17.6 & $<0.0001^{c}$ & 14,417 & 7.7 & $<0.0001$ & 12,919 & 3.2 & $<0.0001$ \\
\hline Other & 1314 & 53.4 & & 4002 & 27.3 & & 4459 & 14.0 & \\
\hline \multicolumn{10}{|l|}{ General health condition } \\
\hline Excellent/very good & 3190 & 17.2 & $<0.0001$ & 10,634 & 8.2 & $<0.0001$ & 7622 & 3.8 & $<0.0001$ \\
\hline Good & 1855 & 28.0 & & 5452 & 13.7 & & 5829 & 5.6 & \\
\hline Fair/poor & 943 & 42.0 & & 2330 & 20.9 & & 3925 & 7.5 & \\
\hline \multicolumn{10}{|l|}{ Source of tap water } \\
\hline Municipal & 5306 & 22.9 & 0.9746 & 16,294 & 10.9 & 0.9501 & 13,218 & 5.4 & $<0.0001$ \\
\hline Public/private well & 589 & 23.0 & & 1768 & 11.0 & & 1962 & 2.6 & \\
\hline \multicolumn{10}{|l|}{ Crowded housing $^{d}$} \\
\hline$\leq 1$ person/room & 4109 & 20.9 & $<0.0001$ & 12,739 & 10.1 & $<0.0001$ & 12,872 & 4.8 & 0.0091 \\
\hline$>1$ person/room & 1806 & 34.2 & & 5490 & 15.7 & & 2401 & 6.5 & \\
\hline \multicolumn{10}{|l|}{ Injected drug user } \\
\hline No/unknown & - & - & - & 18,377 & 8.4 & 0.5850 & 17,294 & 4.8 & $<0.0001$ \\
\hline Yes & - & - & & 48 & 11.0 & & 95 & 18.5 & \\
\hline
\end{tabular}

${ }^{a}$ Weighted percentages

${ }^{\mathrm{b}}$ Rao-Scott chi-square test used

'Unweighted Wald chi-square used

${ }^{d}$ Calculated as total number of individuals living in a household divided by number of rooms in the home (excluding bathroom and kitchen) 
Table 2 Distribution of blood levels for lead and cadmium (in $\mu \mathrm{g} / \mathrm{mL}$ ) among non-smoking NHANES participants, 1999-2012

\begin{tabular}{|c|c|c|c|c|c|c|c|c|c|c|c|c|}
\hline \multirow[t]{2}{*}{ Survey years } & \multirow[t]{2}{*}{ Pathogen } & \multirow[t]{2}{*}{$N$} & \multicolumn{5}{|l|}{ Blood lead } & \multicolumn{5}{|l|}{ Blood cadmium } \\
\hline & & & $\begin{array}{l}\text { Weighted Geometric } \\
\text { Mean }(95 \% \mathrm{Cl})\end{array}$ & $\begin{array}{l}25^{\text {th }} \\
P\end{array}$ & $\begin{array}{l}50^{\text {th }} \\
P\end{array}$ & $\begin{array}{l}75^{\text {th }} \\
P\end{array}$ & $\begin{array}{l}\text { \% below } \\
\text { LOD }^{\mathrm{a}}\end{array}$ & $\begin{array}{l}\text { Weighted Geometric } \\
\text { Mean }(95 \% \mathrm{Cl})\end{array}$ & $\begin{array}{l}25^{\text {th }} \\
P\end{array}$ & $\begin{array}{l}50^{\text {th }} \\
P\end{array}$ & $\begin{array}{l}75^{\text {th }} \\
P\end{array}$ & $\begin{array}{l}\text { \% below } \\
\text { LOD }^{\mathrm{b}}\end{array}$ \\
\hline \multirow[t]{3}{*}{ 1999-2000 } & $\begin{array}{l}\text { Helicobacter } \\
\text { pylori }\end{array}$ & 5994 & $1.50(1.43-1.57)$ & 0.94 & 1.43 & 2.18 & 0.80 & $0.33(0.31-0.36)$ & 0.20 & 0.29 & 0.40 & 35.1 \\
\hline & Negative & 4073 & $1.41(1.34-1.47)$ & 0.88 & 1.34 & 2.01 & 0.96 & $0.31(0.29-0.34)$ & 0.20 & 0.26 & 0.38 & 39.6 \\
\hline & Positive & 1921 & $1.86(1.77-1.95)$ & 1.18 & 1.76 & 2.71 & 0.26 & $0.40(0.37-0.43)$ & 0.23 & 0.36 & 0.49 & 20.4 \\
\hline \multirow[t]{3}{*}{$\begin{array}{l}\text { 1999-2004, } \\
\text { 2009-2010 }\end{array}$} & $\begin{array}{l}\text { Toxoplasma } \\
\text { gondii }\end{array}$ & 18,425 & $1.13(1.10-1.16)$ & 0.72 & 1.10 & 1.69 & 0.95 & $0.25(0.24-0.25)$ & 0.15 & 0.20 & 0.38 & 44.7 \\
\hline & Negative & 16,449 & $1.09(1.07-1.12)$ & 0.70 & 1.09 & 1.60 & 1.01 & $0.24(0.24-0.25)$ & 0.15 & 0.19 & 0.34 & 46.4 \\
\hline & Positive & 1976 & $1.44(1.40-1.49)$ & 1.00 & 1.40 & 2.10 & 0.47 & $0.29(0.28-0.31)$ & 0.17 & 0.29 & 0.40 & 30.4 \\
\hline \multirow[t]{3}{*}{ 1999-2012 } & $\begin{array}{l}\text { Hepatitis B } \\
\text { virus }\end{array}$ & 17,389 & $1.41(1.38-1.44)$ & 0.90 & 1.40 & 2.10 & 0.51 & $0.30(0.30-0.31)$ & 0.20 & 0.30 & 0.44 & 26.4 \\
\hline & Negative & 16,231 & $1.39(1.36-1.42)$ & 0.90 & 1.39 & 2.09 & 0.53 & $0.30(0.29-0.30)$ & 0.19 & 0.29 & 0.42 & 14.7 \\
\hline & Positive & 1158 & $1.80(1.72-1.88)$ & 1.23 & 1.77 & 2.61 & 0.18 & $0.41(0.38-0.43)$ & 0.27 & 0.40 & 0.59 & 27.1 \\
\hline
\end{tabular}

$\angle O D$ limit of detection

${ }^{\mathrm{a}} \mathrm{LOD}=0.30$ (1999-2004), 0.25 (2005-2012)

${ }^{b}$ LOD $=0.30$ (1999-2002). 0.20 (2003-2010), 0.16 (2011-2012)

the LOD; the GM for blood cadmium was $0.25(95 \%$ $\mathrm{CI}=0.24-0.25$ ), with $44.7 \%$ below the LOD (Table 2). For the association between $T$. gondii seropositivity and metal concentrations (Figs. 2 and 3), the adjusted odds ratios associated with a doubling of blood lead and cadmium were 1.19 (95\% $\mathrm{CI}=1.12-1.28)$ and 1.06 (95\% CI $=0.96-1.18$ ), respectively (Table 3 ). There was a significant trend $(p<0.0001)$ in increasing seroprevalence by quartiles of lead (Table 3). The association between lead and T. gondii seropositivity was slightly weaker among children under 13 years old (Table 5, $\mathrm{AOR}=1.12 ; 95 \% \mathrm{CI}=0.84-1.49$, per doubling of blood lead) compared to those 13-35 years old $(\mathrm{AOR}=1.25 ; 95 \% \mathrm{CI}=1.12-1.40)$ and those over 35 years old $(\mathrm{AOR}=1.21 ; 95 \% \mathrm{CI}=1.07-1.37)$ (Additional file 1, Tables S1 and S2). Lead and cadmium concentrations were only slightly correlated (Pearson's $r=$ 0.24 ), and no evidence was found to suggest additive or multiplicative interaction between lead and cadmium exposure in association with $T$. gondii seropositivity (Table 6).

\section{Hepatitis B virus}

After excluding HBV-vaccinated participants and those with unknown vaccine status, exposure and HBV serology data were available for 17,389 non-smoking participants $\geq 6$ years old from 7 NHANES cycles (1999-2012) (Fig. 1c). Overall seroprevalence for anti-HBc was $4.9 \%$. Seroreactivity significantly varied by age, gender, race, family income level, country of birth origin, general health condition, source of home tap water, crowded housing, and using illegal/illicit injectable drugs (Table 1). The blood lead GM concentration for all participants was 1.41 (95 \% CI=1.38-1.44), with $0.5 \%$ of results below the LOD; the GM for blood cadmium was 0.30
(95\% CI $=0.30-0.31$ ), with $26.4 \%$ below the LOD (Table 2). In examining the association between anti$\mathrm{HBc}$ seropositivity and blood concentrations (Figs. 2 and 3 ), the adjusted odds associated with a 2-fold increase (doubling) in blood levels of lead and cadmium were $1.19(95 \% \mathrm{CI}=1.08-1.32)$ and $1.38(95 \% \mathrm{CI}=1.23-$ 1.55) respectively (Table 3 ). There were significant trends in increasing seroprevalence by percentiles of lead $(\mathrm{p}=0.0077)$ and cadmium $(p<0.0001)$ (Table 3). Lead and cadmium concentrations were only slightly correlated (Pearson's $r=0.31$ ), and no evidence was found to suggest additive or multiplicative interaction between lead and cadmium exposure in association with HBV seropositivity (Table 7).

We considered serum iron in all analyses, however, we excluded it from the final models because it was statistically insignificant in all models, did not impact the coefficients of lead and cadmium, and reduced the effective sample size due to missing data.

\section{Discussion}

We observed statistically significant increased odds of elevated blood lead and cadmium levels among nonsmoking NHANES participants seropositive for $H$. pylori, T. gondii, and HBV. The associations between lead and cadmium exposures and $H$. pylori seropositivity were strongly pronounced among participants under 13 years of age, particularly for lead. For each of the three chronic infections, non-smoking participants had an approximately $20 \%$ increase in odds of being seropositive for each doubling of blood lead levels (Table 3). For HBV and H. pylori infections, a doubling of blood cadmium levels corresponded to nearly a $40 \%$ increase in odds of being seropositive (Table 3). We found no 
a

$$
4.5
$$

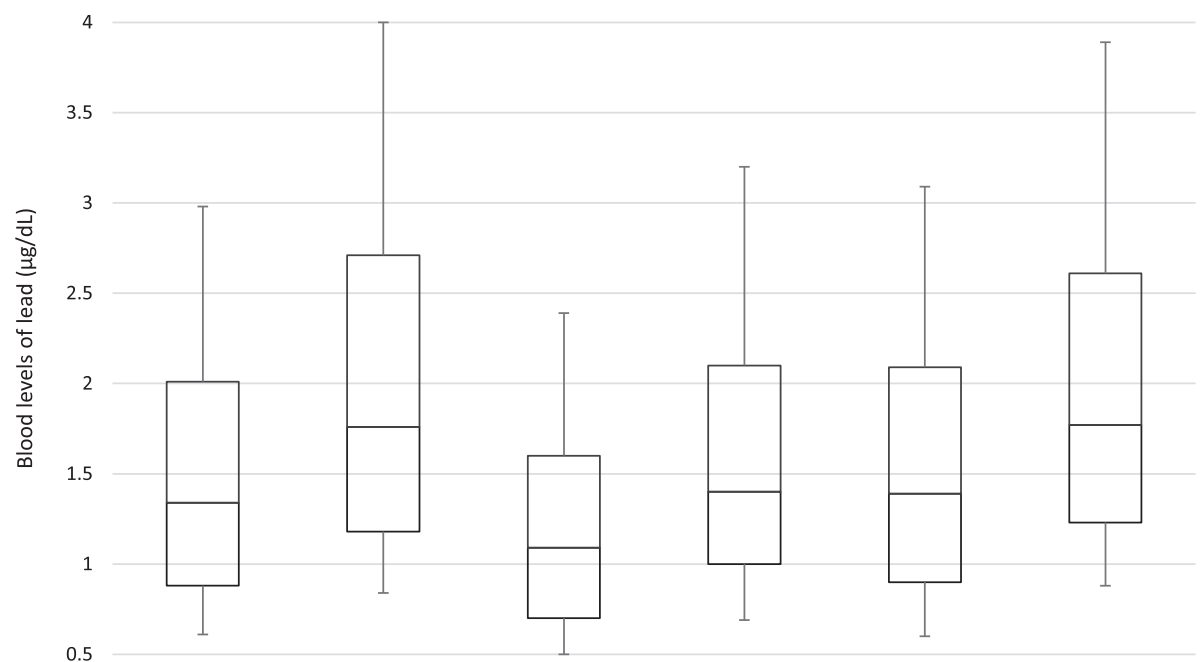

0

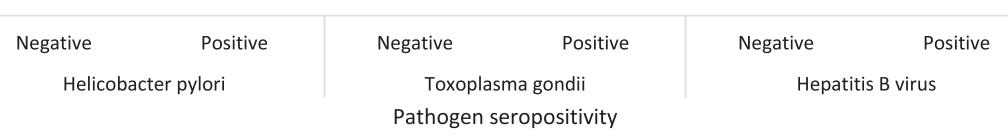

b

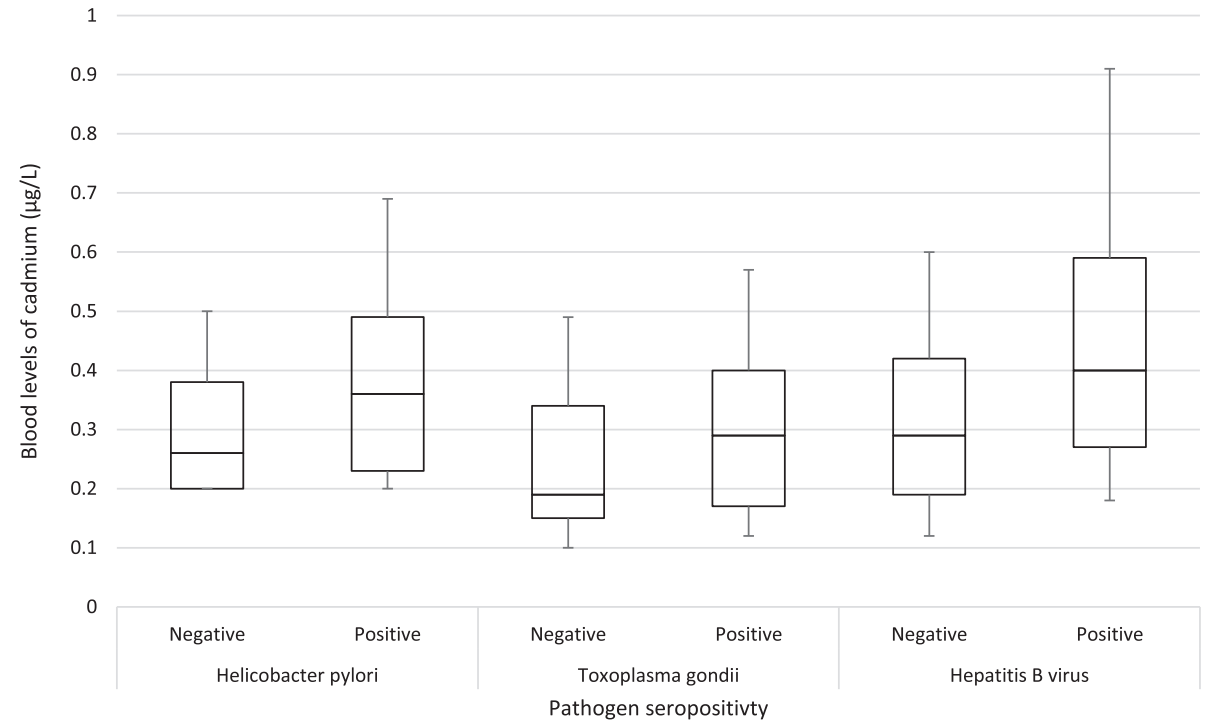

Fig. 2 Box plots of $10^{\text {th }}, 25^{\text {th }}, 50^{\text {th }}, 75^{\text {th }}$, and $90^{\text {th }}$ percentiles for blood levels of lead (panel a) and cadmium (panel b) by pathogen seropositivity among non-smoking NHANES participants, 1999-2012

evidence of additive or multiplicative interaction between lead and cadmium. These results support the growing evidence that heavy metal exposure has deleterious effects on the immune response.

Suppression of the immune response may lead to increased susceptibility of the host to chronic infection. In addition to an immunotoxic effect, heavy metals may also influence the severity of infection. An in vitro study found that cadmium-induced oxidative stress increased influenza virus replication in Madin-Darby canine kidney (MDCK) cells [31]. An experimental study in mice suggested that during a Coxsackievirus B3 infection, 
a

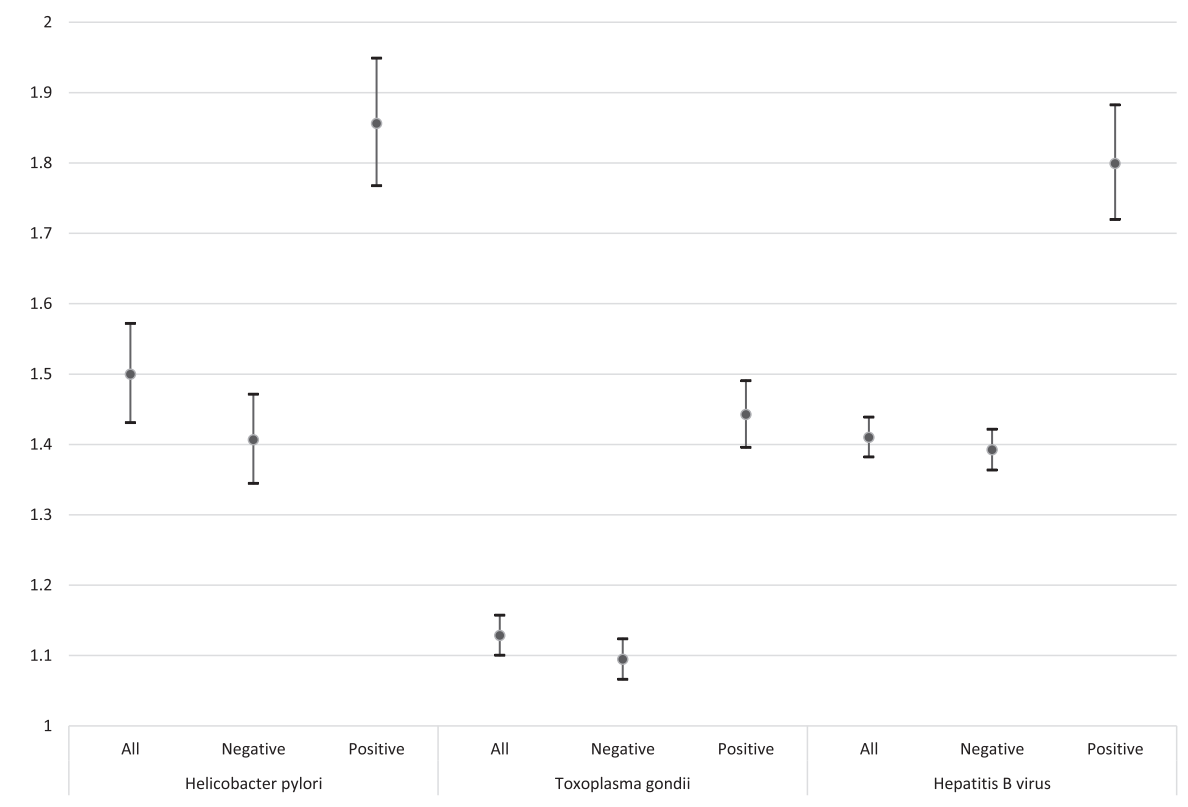

b

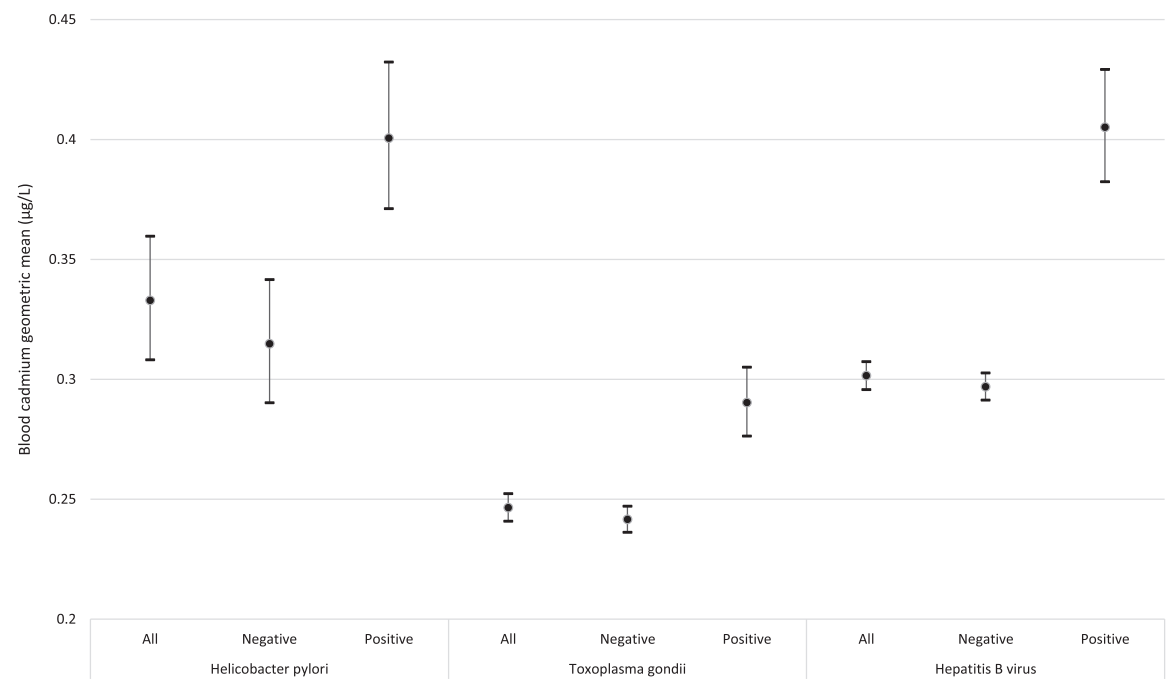

Fig. 3 Geometric means and $95 \%$ confidence intervals of blood metal of lead (panel a) and cadmium (panel b) by pathogen seropositivity among non-smoking NHANES participants, 1999-2012

levels of mercury flux between tissues such that higher levels were retained in infected organs [32]. Another mouse study reported that pretreatment with a single dose of cadmium or manganese increased the severity of symptoms and mortality to sub-lethal viral infections, including Venezuelan Equine Encephalitis virus [33].

Our analysis contributes to the growing body of literature that has used NHANES data to examine associations between heavy metal exposures and infections. Previous NHANES analyses have reported associations between chronic HBV infections and blood mercury levels in women of child-bearing age [34], higher blood cadmium levels among HIV-infected individuals [35], elevated blood lead levels and an increased risk of herpes simplex virus type 2 infections [36], as well as an inverse association between urinary arsenic and Varicella Zoster virus seroprevalence [37].

HBV is a bloodborne virus that attacks the liver. HBV pathogenesis results from interactions between the virus and the host's immune system. Immunosuppression of the host can result in chronic HBV infections. Lead and cadmium are hepatotoxic $[38,39]$ and have been shown 
Table 3 Seropositivity associated with blood lead and cadmium levels, for each two-fold increase and across percentiles, among non-smoking NHANES participants, 1999-2012. All subjects

\begin{tabular}{|c|c|c|c|c|c|c|}
\hline \multirow[t]{2}{*}{ Heavy metal } & \multicolumn{2}{|l|}{ H. pylori } & \multicolumn{2}{|l|}{ T. gondii } & \multicolumn{2}{|c|}{ Hepatitis B virus } \\
\hline & $\begin{array}{l}\text { Positive } \\
\text { (Weighted \%) }\end{array}$ & AOR $(95 \% C l)^{a, b}$ & $\begin{array}{l}\text { Positive } \\
\text { (Weighted \%) }\end{array}$ & AOR $(95 \% \mathrm{Cl})^{\mathrm{a}, \mathrm{c}}$ & $\begin{array}{l}\text { Positive } \\
\text { (Weighted \%) }\end{array}$ & $\mathrm{AOR}(95 \% \mathrm{Cl})^{\mathrm{a}, \mathrm{d}}$ \\
\hline Per doubling of blood lead & 23.1 & $1.22(1.12-1.34)^{\mathrm{e}}$ & 11.0 & $1.19(1.12-1.28)$ & 4.9 & $1.19(1.08-1.32)$ \\
\hline \multicolumn{7}{|l|}{ Blood lead concentration ( $\mu \mathrm{g} / \mathrm{dL})$} \\
\hline Quartile 1 & 12.7 & Ref & 5.6 & Ref & 2.2 & Ref \\
\hline Quartile 2 & 19.9 & $1.31(0.98-1.75)$ & 8.7 & $1.20(0.93-1.54)$ & 4.0 & $1.41(1.04-1.93)$ \\
\hline Quartile 3 & 24.3 & $1.39(1.13-1.72)$ & 12.8 & $1.53(1.22-1.91)$ & 6.1 & $1.79(1.31-2.43)$ \\
\hline Quartile 4 & 34.1 & $1.69(1.33-2.15)$ & 16.5 & $1.56(1.28-1.90)$ & 7.1 & $1.70(1.23-2.35)$ \\
\hline$p$ for trend & $<0.0001$ & & $<0.0001$ & & 0.0077 & \\
\hline Per doubling of blood cadmium & 23.1 & $1.37(1.17-1.62)$ & 11.0 & $1.06(0.96-1.18)$ & 4.9 & $1.38(1.23-1.55)$ \\
\hline \multicolumn{7}{|l|}{ Blood cadmium concentration ( $\mu \mathrm{g} / \mathrm{L})$} \\
\hline Tertile 1 & 13.4 & Ref & 6.9 & Ref & 2.8 & Ref \\
\hline Tertile 2 & 22.1 & $1.51(1.16-1.97)$ & 9.7 & $1.34(1.03-1.74)$ & 3.8 & $1.09(0.84-1.43)$ \\
\hline Tertile 3 & 30.5 & $1.48(1.25-1.76)$ & 14.4 & $1.32(1.03-1.69)$ & 7.7 & $1.72(1.32-2.25)$ \\
\hline$p$ for trend & $<0.0001$ & & 0.1438 & & $<0.0001$ & \\
\hline
\end{tabular}

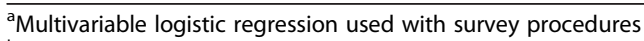

${ }^{b}$ Adjusted for age, gender, race/ethnicity, country of birth origin, family income, self-reported general health condition, tap water source, and household crowding

${ }^{c}$ Adjusted for NHANES cycle, age, gender, race/ethnicity, country of birth origin, family income, self-reported general health condition, and household crowding

${ }^{\mathrm{d}}$ Adjusted for age, gender, race/ethnicity, country of birth origin, family income, self-reported general health condition, and use of illicit/street injected drugs

${ }^{\mathrm{e}}$ Bolded font denotes statistically significant $(a<0.05)$

to increase viral activity [31, 40]. In addition, dietary cadmium has been shown to enhance the progression of hepatocellular tumors in HBV-infected mice [41]. A recent study in China found decreased HBV surface antibody (HBsAb) levels among preschool children exposed to lead from electronic and electrical waste (e-waste) [42]. The authors reported almost $50 \%$ of children with chronic lead exposure failed to develop sufficient immunity against HBV in response to vaccination; therefore, their immune systems may be more susceptible to HBV infection in the future. Another study conducted in Babylon found blood levels of lead to be significantly higher in HBV patients compared to healthy controls [43].
T. gondii, an obligate intracellular protozoan, is one of the most widespread zoonotic parasites in the world [44]. When oocysts are ingested by an intermediate host such as humans, they migrate in the host's body and form permanent cysts in various organs and tissues [45]. Toxoplasmosis is lifelong infection that has the potential to reactivate and cause severe disease and even death in immunocompromised individuals. Existing data on the effect of lead and cadmium on chronic toxoplasmosis are lacking; however, lead has been suggested to inhibit intracellular killing of Leishmania parasites [46]. Although age-specific associations between blood lead and $T$. gondii seropositivity were relatively similar, among

Table 4 Effect of interaction between blood lead and blood cadmium levels on odds of H. pylori seropositivity, NHANES 1999-2000

\begin{tabular}{|c|c|c|c|c|c|}
\hline \multirow[t]{3}{*}{ Blood lead levels } & \multicolumn{5}{|c|}{ Blood cadmium levels } \\
\hline & \multicolumn{2}{|l|}{$<$ Median } & \multicolumn{2}{|l|}{$\geq$ Median } & \multirow{2}{*}{$\begin{array}{l}\text { AOR }(95 \% \mathrm{Cl}) \\
\text { within } \mathrm{Pb} \text { strata }\end{array}$} \\
\hline & N (Weighted \%) & AOR (95 \% Cl) & N (Weighted \%) & AOR $(95 \% \mathrm{Cl})$ & \\
\hline \multirow[t]{2}{*}{$<$ Median } & $1662(11.6)$ & 1.0 & $1074(23.7)$ & $1.38(1.03-1.97)$ & $1.20(0.88-1.64)$ \\
\hline & & & & $P=0.0337$ & $P=0.2597$ \\
\hline \multirow[t]{2}{*}{$\geq$ Median } & $1436(22.1)$ & $1.43(1.10-1.87)$ & $4073(35.2)$ & $1.63(1.27-2.10)$ & $1.27(1.02-1.57)$ \\
\hline & & $P=0.0082$ & & $P=0.0002$ & $P=0.0313$ \\
\hline \multirow[t]{2}{*}{ AOR $(95 \%$ Cl) within Cd strata } & & $1.32(0.97-1.79)$ & & $1.27(0.98-1.65)$ & \\
\hline & & $P=0.0795$ & & $P=0.0689$ & \\
\hline
\end{tabular}

Measure of interaction on additive scale: RERI $(95 \% \mathrm{Cl})=-0.21(-0.74-0.32)$

Measure of interaction on multiplicative scale: ratio of ORs $(95 \% \mathrm{Cl})=0.82(0.56-1.21) ; P=0.3183$

AORs are adjusted for age, gender, race/ethnicity, country of birth origin, family income, self-reported general health condition, tap water source, and household crowding 
Table 5 Seropositivity associated with blood lead and cadmium levels, for each two-fold increase and across percentiles, among non-smoking NHANES participants, 1999-2012. Children under 13 years of age ${ }^{a}$

\begin{tabular}{|c|c|c|c|c|}
\hline \multirow[t]{2}{*}{ Heavy metal } & \multicolumn{2}{|l|}{ H. pylori } & \multicolumn{2}{|l|}{ T. gondii } \\
\hline & Positive (Weighted \%) & AOR $(95 \% C l)^{\mathrm{b}, \mathrm{c}}$ & Positive (Weighted \%) & $\operatorname{AOR}(95 \% \mathrm{Cl})^{\mathrm{b}, \mathrm{d}}$ \\
\hline Per doubling of blood lead & 7.3 & $2.61(1.85-3.67)^{\mathrm{e}}$ & 3.5 & $1.12(0.84-1.49)$ \\
\hline \multicolumn{5}{|l|}{ Blood lead concentration $(\mu \mathrm{g} / \mathrm{dL})$} \\
\hline Quartile 1 & 0.8 & Ref & 1.8 & Ref \\
\hline Quartile 2 & 4.5 & $5.26(1.92-14.4)$ & 3.0 & $1.46(0.57-3.73)$ \\
\hline Quartile 3 & 5.8 & $4.75(1.61-14.0)$ & 3.0 & $1.17(0.46-2.95)$ \\
\hline Quartile 4 & 15.5 & $21.2(8.32-53.8)$ & 5.7 & $1.82(0.75-4.43)$ \\
\hline$p$ for trend & $<0.0001$ & & 0.1825 & \\
\hline Per doubling of blood cadmium & 7.3 & $2.02(1.29-3.15)$ & 3.5 & $1.10(0.74-1.63)$ \\
\hline \multicolumn{5}{|l|}{ Blood cadmium concentration ( $\mu \mathrm{g} / \mathrm{L}$ ) } \\
\hline Tertile 1 & 5.5 & Ref & 2.1 & Ref \\
\hline Tertile 2 & 9.9 & $2.75(1.30-5.83)$ & 4.1 & $1.46(0.63-3.36)$ \\
\hline Tertile 3 & 10.5 & $2.39(1.35-4.20)$ & 4.2 & $1.11(0.48-2.56)$ \\
\hline$p$ for trend & 0.0005 & & 0.8214 & \\
\hline
\end{tabular}

${ }^{\mathrm{a}}$ Only two children under 13 were positive for Hepatitis B so it was not considered

${ }^{\mathrm{b}}$ Multivariable logistic regression used with survey procedures

'Adjusted for age, gender, race/ethnicity, country of birth origin, family income, self-reported general health condition, tap water source, and household crowding ${ }^{\mathrm{d}}$ Adjusted for NHANES cycle, age, gender, race/ethnicity, country of birth origin, family income, self-reported general health condition, and household crowding

eBolded font denotes statistically significant $(a<0.05)$

children under 13 years old, the association was slightly weaker compared to older age groups. One of the most common routes of transmission for T. gondii to humans in the United States is suspected to be raw meat consumption [45]; therefore, in addition to having more opportunities to be infected as one ages, eating habits in adulthood may also contribute to this observed association with older age.

Half of the world's population is infected with $H$. pylori [47]. The bacterium colonizes the inner mucus layer of the stomach epithelium, but the majority of infections remain asymptomatic. Up to $20 \%$ of $H$. pylori infections lead to severe chronic disease outcomes, including chronic gastritis, peptic ulcer, gastric mucosa- associated lymphoid tissue (MALT) lymphoma, and gastric cancer [48-51]. While there are no published data describing the association between lead and cadmium and chronic helicobacteriosis, researchers have suggested that maintaining metal homeostasis, including cadmium levels, is critical for $H$. pylori to adapt to and survive in the gastric environment [52].

The stronger association between H. pylori seropositivity and lead and cadmium exposures among children may be due to an increased vulnerability or susceptibility, due to increased and faster absorption of these metals during a time when hygienic factors may also make them more likely to be exposed to H. pylori. Although we controlled for numerous available factors

Table 6 Effect of interaction between blood lead and blood cadmium levels on odds of T. gondii seropositivity, NHANES 1999-2004, 2009-10

\begin{tabular}{|c|c|c|c|c|c|}
\hline \multirow[t]{3}{*}{ Blood lead levels } & \multicolumn{5}{|c|}{ Blood cadmium levels } \\
\hline & \multicolumn{2}{|l|}{$<$ Median } & \multicolumn{2}{|l|}{$\geq$ Median } & \multirow{2}{*}{$\begin{array}{l}\text { AOR }(95 \% \mathrm{Cl}) \\
\text { within Pb strata }\end{array}$} \\
\hline & N (Weighted \%) & AOR $(95 \% \mathrm{Cl})$ & N (Weighted \%) & AOR (95 \% Cl) & \\
\hline \multirow[t]{2}{*}{$<$ Median } & $4629(5.2)$ & 1.0 & $3892(9.3)$ & $1.24(0.978-1.59)$ & $1.26(0.94-1.69$ \\
\hline & & & & $P=0.0805$ & $P=0.1222$ \\
\hline \multirow[t]{2}{*}{$\geq$ Median } & $4101(10.4)$ & $1.45(1.17-1.79)$ & $5803(17.0)$ & $1.64(1.30-2.07)$ & $1.34(0.97-1.85)$ \\
\hline & & $P=0.0007$ & & $P=<0.0001$ & $P=0.0779$ \\
\hline \multirow[t]{2}{*}{ AOR $(95 \%$ Cl) within Cd strata } & & $1.13(0.78-1.62)$ & & $1.41(1.22-1.63)$ & \\
\hline & & $P=0.5244$ & & $P=<0.0001$ & \\
\hline
\end{tabular}

Measure of interaction on additive scale: RERI $(95 \% \mathrm{Cl})=-0.05(-0.42-0.32)$

Measure of interaction on multiplicative scale: ratio of ORs $(95 \% \mathrm{Cl})=0.91(0.69-1.21) P=0.5262$

AORs are adjusted for NHANES cycle, age, gender, race/ethnicity, country of birth origin, family income, self-reported general health condition, and

household crowding 
Table 7 Effect of interaction between blood lead and blood cadmium levels on odds of Hepatitis B seropositivity, NHANES 1999-2012

\begin{tabular}{|c|c|c|c|c|c|}
\hline \multirow[t]{3}{*}{ Blood lead levels } & \multicolumn{5}{|c|}{ Blood cadmium levels } \\
\hline & \multicolumn{2}{|l|}{$<$ Median } & \multicolumn{2}{|l|}{$\geq$ Median } & \multirow{2}{*}{$\begin{array}{l}\text { AOR }(95 \% \mathrm{Cl}) \\
\text { within Pb strat }\end{array}$} \\
\hline & $\mathrm{N}$ (Weighted \%) & AOR $(95 \% \mathrm{Cl})$ & $\mathrm{N}$ (Weighted \%) & AOR $(95 \% \mathrm{Cl})$ & \\
\hline \multirow[t]{2}{*}{$<$ Median } & $4160(2.2)$ & 1.0 & $3622(4.5)$ & $1.51(1.12-2.04)$ & $1.42(1.03-1.98)$ \\
\hline & & & & $P$ & $P=0.0310$ \\
\hline \multirow[t]{2}{*}{$\geq$ Median } & $3011(4.0)$ & $1.23(0.86-1.76)$ & $6596(7.9)$ & $1.98(1.51-2.61)$ & $1.67(1.23-2.25)$ \\
\hline & & $P=0.2503$ & & $P=<0.0001$ & $P=0.0008$ \\
\hline \multirow{2}{*}{ AOR $(95 \%$ Cl) within Cd strata } & & $1.12(0.79-1.60)$ & & $1.35(1.06-1.72)$ & \\
\hline & & $P=0.5209$ & & $P=0.0155$ & \\
\hline
\end{tabular}

Measure of interaction on additive scale: RERI $(95 \% \mathrm{Cl})=0.24(-0.28-0.76)$

Measure of interaction on multiplicative scale: ratio of ORs $(95 \% \mathrm{Cl})=1.07(0.71-1.61) ; P=0.7622$

AORs are adjusted for age, gender, race/ethnicity, country of birth origin, family income, self-reported general health condition, use of illicit/street injected drugs

related to socioeconomic status and living conditions (income, crowding), these associations could also reflect a shared environmental susceptibility that we were unable to fully control for in our analysis.

We found no evidence to suggest either additive or multiplicative interaction between elevated lead and cadmium levels and their association with seropositivity. Lead and cadmium share common environmental exposure routes through contaminated food, water, and soil. Individual toxic metals can interact with toxic and essential metals in various tissues [53]. Mixed-metal exposure may yield synergistic interactions, or even novel effects not seen in single metal exposures [54, 55]; however, information on the interaction of low-dose toxic metal mixtures is lacking $[5,56]$. Studies have reported that exposure to lead increased the renal response to low levels of cadmium [57], and a dose-dependent interaction between prenatal co-exposure to lead and cadmium has been observed [58]. Because lead and cadmium have common, as well as distinctive, binding sites and mechanisms of action, the pathophysiological effects caused by each metal alone may be exacerbated during co-exposure [59]. It remains unclear whether our lack of evidence for interaction was because synergistic interaction does not influence immunomodulatory effects or because our method of examining co-exposure was inadequate. Furthermore, including both lead and cadmium levels as covariates in a single multivariable model (rather than separately in individual models as reported here), did not significantly change the observed effects (data not shown).

Continuous NHANES collects valuable health information from a national, representative sample of the United States population, making it an effective tool for hypothesis generation and exploring biomarker data for chemical risk assessments [60]. Nonetheless, we recognize the inherent limitations of its cross-sectional design that prevent us from inferring causality. In addition, combining datasets across multiple survey years can be a limitation, depending on the covariates of interest. Questions and medical exams are not continuous across the survey years. In addition, several questionnaires and metal exposure assessments are administered to only subgroups (e.g. adults $\geq 20$ years old, females of child-bearing age, or a special one-third subsample of adults). Our goal was to maintain the largest cohort as possible for consistency and increased power. Despite these limitations, this study provides risk factor data that can inform future environmental assessments and prospective human studies to better link cause and effect for heavy metal exposure and risk of chronic infections.

\section{Conclusions}

Environmental exposure to lead and cadmium, even at chronic low-level doses, remains a significant public health concern [54]. The results of this cross-sectional human health survey suggest that the immunological effects of lead and cadmium toxicity may result in an increased susceptibility to chronic infections. While the mechanisms of immunotoxicity vary by metal type, exposure dose, temporality to infection, severity of infection, and genetic factors $[1,54,61,62]$, increased environmental contamination with heavy metals will likely contribute to an increased incidence of chronic infections in human populations.

\section{Additional file}

Additional file 1: Supplemental Tables. Description of data: Seropositivity associated with blood lead and cadmium levels among non-smoking NHANES participants, by age groups 13-35 and 35 and over. (PDF $238 \mathrm{~kb}$ )

Competing interests

The authors declare that they have no competing interests. 


\section{Authors' contributions}

WK participated in the design of the study, conducted data analysis, participated in data interpretations, and drafted the manuscript. TW conceived the study, participated in study design and data interpretations, conducted data analysis, and critically revised the manuscript. Both authors read and approved the final manuscript.

\section{Acknowledgements}

The manuscript has been subjected to the U.S. Environmental Protection Agency's peer review and has been approved for publication. We thank Shannon M. Griffin of the U.S. EPA for her review and comments. The views expressed in this paper are those of the authors and do not necessarily reflect the views or policies of the U.S. EPA. This project was supported in part by an appointment to the Internship/Research Participation Program at the Office of Research and Development, U.S. EPA, administered by the Oak Ridge Institute for Science and Education through an interagency agreement between the U.S. Department of Energy and EPA.

The views expressed in this paper are those of the authors and do not necessarily reflect the views or policies of the U.S. Environmental Protection Agency.

\section{Author details}

'RTI Health Solutions, 3040 Cornwallis Road, Post Office Box 12194, Research Triangle Park, NC 27709-2194, USA. ${ }^{2}$ Oak Ridge Institute for Science and Education, Oak Ridge, TN 37831, USA. ${ }^{3}$ United States Environmental Protection Agency, Office of Research and Development, National Health \& Environmental Effects Research Laboratory, Environmental Public Health Division, Chapel Hill, NC 27514, USA.

\section{Received: 3 September 2015 Accepted: 4 February 2016} Published online: 11 February 2016

\section{References}

1. Bernier J, Brousseau P, Krzystyniak K, Tryphonas H, Fournier M. Immunotoxicity of heavy metals in relation to Great Lakes. Environ Health Perspect. 1995;103 Suppl 9:23-34.

2. Razani-Boroujerdi S, Edwards B, Sopori ML. Lead stimulates lymphocyte proliferation through enhanced T cell-B cell interaction. J Pharmacol Exp Ther. 1999;288(2):714-9.

3. Krocova Z, Macela A, Kroca M, Hernychova L. The immunomodulatory effect(s) of lead and cadmium on the cells of immune system in vitro. Toxicol In Vitro. 2000;14(1):33-40.

4. Valentino M, Rapisarda V, Santarelli L, Bracci M, Scorcelletti M, Di Lorenzo L, et al. Effect of lead on the levels of some immunoregulatory cytokines in occupationally exposed workers. Hum Exp Toxicol. 2007;26(7):551-6.

5. Mishra KP, Singh VK, Rani R, Yadav VS, Chandran V, Srivastava SP, et al. Effect of lead exposure on the immune response of some occupationally exposed individuals. Toxicology. 2003;188(2-3):251-9.

6. Marth $\mathrm{E}$, Barth $\mathrm{S}$, Jelovcan $\mathrm{S}$. Influence of cadmium on the immune system. Description of stimulating reactions. Cent Eur J Public Health. 2000;8(1):40-4.

7. Mishra KP. Lead exposure and its impact on immune system: a review. Toxicol In Vitro. 2009;23(6):969-72.

8. Rager JE, Yosim A, Fry RC. Prenatal exposure to arsenic and cadmium impacts infectious disease-related genes within the glucocorticoid receptor signal transduction pathway. Int J Mol Sci. 2014;15(12):22374-91.

9. Garcia-Leston J, Roma-Torres J, Mayan O, Schroecksnadel S, Fuchs D, Moreira $\mathrm{AO}$, et al. Assessment of immunotoxicity parameters in individuals occupationally exposed to lead. J Toxicol Environ Health A. 2012;75(13-15): 807-18.

10. Zelikoff JT, Bowser D, Squibb KS, Frenkel K. Immunotoxicity of low level cadmium exposure in fish: an alternative animal model for immunotoxicological studies. J Toxicol Environ Health. 1995;45(3):235-48.

11. Abadin H, Ashizawa A, Stevens YW, et al. Toxicological Profile for Lead. Atlanta (GA): Agency for Toxic Substances and Disease Registry (US); 2007 Aug. Available from:http://www.ncbi.nlm.nih.gov/books/NBK158766/.

12. Henn SA, Sussell AL, Li J, Shire JD, Alarcon WA, Tak S. Characterization of lead in US workplaces using data from OSHA's integrated management information system. Am J Ind Med. 2011;54(5):356-65.

13. Tsydenova O, Bengtsson M. Chemical hazards associated with treatment of waste electrical and electronic equipment. Waste Manag. 2011;31(1):45-58.
14. Faroon O, Ashizawa A, Wright S, Tucker P, Jenkins K, Ingerman L, Rudisill C. Toxicological profile for cadmium. Atlanta; 2012

15. Andersen O, Nielsen JB, Nordberg GF. Nutritional interactions in intestinal cadmium uptake-possibilities for risk reduction. Biometals. 2004;17(5):543-7.

16. Bernard A. Cadmium \& its adverse effects on human health. Indian J Med Res. 2008:128(4):557-64.

17. Jarup L, Hellstrom L, Alfven T, Carlsson MD, Grubb A, Persson B, et al. Low level exposure to cadmium and early kidney damage: the OSCAR study. Occup Environ Med. 2000;57(10):668-72.

18. Integrated Risk Information System Chemical Assessment Summary for Cadmium (CASRN 7440-43-9). United States Environmental Protection Agency, National Center for Environmental Assessment. Washington, DC. Last revised 3-31-1987. Available fromhttp://cfpub.epa.gov/ncea/iris/iris_ documents/documents/subst/0141_summary.pdf.

19. CDC. National Health and Nutrition Examination Survey Data. Hyattsville: U. S. Department of Health and Human Services, Centers for Disease Control and Prevention, National Center for Health Statistics; 2013.

20. Johnson CL, Paulose-Ram R, Ogden CL, Carroll MD, Kruszon-Moran D, Dohrmann SM, Curtin LR. National health and nutrition examination survey: analytic guidelines, 1999-2010. Vital Health Stat 2. 2013 (161):1-24.

21. CDC. National Health and Nutrition Examination Survey Laboratory Protocol 11: Helicobacter pylori lgG antibodies in serum by enzyme immunoassay. Hyattsville: U.S. Department of Health and Human Services, Centers for Disease Control and Prevention, National Center for Health Statistics; 2008.

22. Miller DT, Paschal DC, Gunter EW, Stroud PE, D'Angelo J. Determination of lead in blood using electrothermal atomisation atomic absorption spectrometry with a L'vov platform and matrix modifier. Analyst. 1987;112(12):1701-4.

23. Parsons PJ, Slavin W. A rapid Zeeman graphite furnace atomic absorption spectrometric method for the determination of lead in blood. Spectrochimica Acta. 1993:48B(6/7):15

24. Stoeppler M, Brandt K. Determination of cadmium in whole blood and urine by electrothermal atomic-absorption spectrophotometry. Fresenius Z Anal Chem. 1980;300:9

25. CDC Division of Laboratory Sciences. Laboratory Protocol Blood Cadmium and Lead Atomic Absorption Spectroscopy. Method No. 1090A/02-OD, Revised August 22, 2001. Atlanta: National Center for Environmental Health; 2001.

26. Jones RL. Laboratory Procedure Manual. In: Lead and Cadmium (ICPMS) in Whole Blood, NHANES 2005-2006. Atlanta: Inorganic Toxicology and Nutrition, Division of Laboratory Sciences, National Center for Environmental Health; 2004. p. 40.

27. Caruso RV, O'Connor RJ, Stephens WE, Cummings KM, Fong GT. Toxic metal concentrations in cigarettes obtained from U.S. smokers in 2009: results from the International Tobacco Control (ITC) United States survey cohort. Int J Environ Res Public Health. 2014;11(1):202-17.

28. Hukkanen J, Jacob 3rd P, Benowitz NL. Metabolism and disposition kinetics of nicotine. Pharmacol Rev. 2005;57(1):79-115

29. Monzon H, Forne M, Esteve M, Rosinach M, Loras C, Espinos JC, et al. Helicobacter pylori infection as a cause of iron deficiency anaemia of unknown origin. World J Gastroenterol. 2013;19(26):4166-71.

30. Hosmer DW, Lemeshow S. Confidence interval estimation of interaction Epidemiology. 1992;3(5):452-6.

31. Checconi P, Sgarbanti R, Celestino I, Limongi D, Amatore D, luvara A, et al. The environmental pollutant cadmium promotes influenza virus replication in MDCK cells by altering their redox state. Int J Mol Sci. 2013;14(2):4148-62.

32. Frisk $P$, Molin $Y$, Ilback NG. Tissue uptake of mercury is changed during the course of a common viral infection in mice. Environ Res. 2008;106(2):178-84.

33. Seth P, Husain MM, Gupta P, Schoneboom A, Grieder BF, Mani H, et al. Early onset of virus infection and up-regulation of cytokines in mice treated with cadmium and manganese. Biometals. 2003;16(2):359-68.

34. Sheehan MC, Burke TA, Breysse PN, Navas-Acien A, McGready J, Fox MA Association of markers of chronic viral hepatitis and blood mercury levels in US reproductive-age women from NHANES 2001-2008: a cross-sectional study. Environ Health. 2012;11:62

35. Xu X, Hu H, Dailey AB, Kearney G, Talbott EO, Cook RL. Potential health impacts of heavy metals on HIV-infected population in USA. PLOS One. 2013;8(9). e74288.

36. $\mathrm{Hu} \mathrm{H}$, Scheidell J, Xu X, Coatsworth AM, Khan MR. Associations between blood lead level and substance use and sexually transmitted infection risk among adults in the United States. Environ Res. 2014;135:21-30.

37. Cardenas A, Smit E, Houseman EA, Kerkvliet NI, Bethel JW, Kile ML. Arsenic exposure and prevalence of the Varicella Zoster virus in the United States: NHANES (2003-2004 and 2009-2010). Environ Health Perspect. 2015;123(6):590-6. 
38. Mudipalli A. Lead hepatotoxicity \& potential health effects. Indian J Med Res. 2007;126(6):518-27.

39. Rikans LE, Yamano T. Mechanisms of cadmium-mediated acute hepatotoxicity. J Biochem Mol Toxicol. 2000;14(2):110-7.

40. Gainer JH. Lead aggravates viral disease and represses the antiviral activity of interferon inducers. Environ Health Perspect. 1974;7:113-9.

41. Sell S, llic Z. Dietary cadmium may enhance the progression of hepatocellular tumors in hepatitis B transgenic mice. Carcinogenesis. 1994; 15(9):2057-60.

42. Xu X, Chen X, Zhang J, Guo P, Fu T, Dai Y, et al. Decreased blood hepatitis B surface antibody levels linked to e-waste lead exposure in preschool children. J Hazard Mater. 2015;298:122-8.

43. Al-Jubbawy AAHS, Wtwt MAA, Shirafy ANA. Correlation of some trace elements and chronic hepatitis B infections in Babylon. J Nat Sci Res. 2013;3(6):6.

44. Robert-Gangneux F, Darde ML. Epidemiology of and diagnostic strategies for toxoplasmosis. Clin Microbiol Rev. 2012;25(2):264-96.

45. Webster JP, Lamberton PH, Donnelly CA, Torrey EF. Parasites as causative agents of human affective disorders? The impact of anti-psychotic, moodstabilizer and anti-parasite medication on Toxoplasma gondii's ability to alter host behaviour. Proc Biol Sci. 2006;273(1589):1023-30.

46. Mauel J, Ransijn A, Buchmuller-Rouiller Y. Lead inhibits intracellular killing of Leishmania parasites and extracellular cytolysis of target cells by macrophages exposed to macrophage activating factor. J Leukoc Biol. 1989;45(5):401-9.

47. Dorer MS, Talarico S, Salama NR. Helicobacter pylori's unconventional role in health and disease. PLoS Pathog. 2009;5(10):e1000544.

48. Marshall BJ, Warren JR. Unidentified curved bacilli in the stomach of patients with gastritis and peptic ulceration. Lancet. 1984;1(8390):1311-5.

49. Suzuki R, Shiota S, Yamaoka Y. Molecular epidemiology, population genetics, and pathogenic role of Helicobacter pylori. Infect Genet Evol. 2012;12(2):203-13.

50. Ruggiero P. Helicobacter pylori and inflammation. Curr Pharm Des. 2010; 16(38):4225-36.

51. Dooley CP, Cohen H, Fitzgibbons PL, Bauer M, Appleman MD, Perez-Perez $\mathrm{Gl}$, et al. Prevalence of Helicobacter pylori infection and histologic gastritis in asymptomatic persons. N Engl J Med. 1989;321(23):1562-6.

52. Stahler FN, Odenbreit S, Haas R, Wilrich J, Van Vliet AH, Kusters JG, et al. The novel Helicobacter pylori CznABC metal efflux pump is required for cadmium, zinc, and nickel resistance, urease modulation, and gastric colonization. Infect Immun. 2006;74(7):3845-52.

53. Diacomanolis $\mathrm{V}$, Noller BN, Ng JC. Bioavailability and pharmacokinetics of arsenic are influenced by the presence of cadmium. Chemosphere. 2014;112:203-9.

54. Wang G, Fowler BA. Roles of biomarkers in evaluating interactions among mixtures of lead, cadmium and arsenic. Toxicol Appl Pharmacol. 2008;233(1):92-9.

55. Exon $\mathrm{JH}$, Koller LD, Kerkvliet NI. Lead-cadmium interaction: effects on viral-induced mortality and tissue residues in mice. Arch Environ Health. 1979:34(6):469-75.

56. Cobbina SJ, Chen Y, Zhou Z, Wu X, Feng W, Wang W, et al. Low concentration toxic metal mixture interactions: effects on essential and nonessential metals in brain, liver, and kidneys of mice on sub-chronic exposure. Chemosphere. 2015;132:79-86.

57. Hambach R, Lison D, D'Haese PC, Weyler J, De Graef E, De Schryver A, et al. Co-exposure to lead increases the renal response to low levels of cadmium in metallurgy workers. Toxicol Lett. 2013;222(2):233-8.

58. Kim Y, Ha EH, Park H, Ha M, Kim Y, Hong YC, et al. Prenatal lead and cadmium co-exposure and infant neurodevelopment at 6 months of age: the Mothers and Children's Environmental Health (MOCEH) study. Neurotoxicology. 2013;35:15-22.

59. Clemow YH, Wilkie MP. Effects of Pb plus Cd mixtures on toxicity, and internal electrolyte and osmotic balance in the rainbow trout (Oncorhynchus mykiss). Aquat Toxicol. 2015;161:176-88.

60. Sobus JR, DeWoskin RS, Tan YM, Pleil JD, Phillips MB, George BJ, et al. Uses of NHANES biomarker data for chemical risk assessment: trends, challenges, and opportunities. Environ Health Perspect. 2015;123(10):919-27.

61. Laschi-Loquerie A, Eyraud A, Morisset D, Sanou A, Tachon P, Veysseyre C, et al. Influence of heavy metals on the resistance of mice toward infection. Immunopharmacol Immunotoxicol. 1987;9(2-3):235-41.

62. Shrivastava R, Upreti RK, Seth PK, Chaturvedi UC. Effects of chromium on the immune system. FEMS Immunol Med Microbiol. 2002;34(1):1-7.

\section{Submit your next manuscript to BioMed Central and we will help you at every step:}

- We accept pre-submission inquiries

- Our selector tool helps you to find the most relevant journal

- We provide round the clock customer support

- Convenient online submission

- Thorough peer review

- Inclusion in PubMed and all major indexing services

- Maximum visibility for your research

Submit your manuscript at www.biomedcentral.com/submit
Biomed Central 